Journal of Accident and Emergency Medicine 1995 12, 34-39

\title{
Out-of-hospital cardiac arrest: two and a half years experience of an accident and emergency department in Hong Kong
}

\author{
T.W.WONG \& K.C. YEUNG
}

Accident \& Emergency Department, Kwong Wah Hospital, 25 Waterloo Road, Yaumati, Kowloon, Hong Kong

\section{SUMMARY}

The results are presented of $2 \frac{1}{2}$ years of experience of patients with out-of-hospital cardiac arrests who were resuscitated in an accident and emergency department (A\&E) attached to an acute district hospital in Hong Kong. Out of 263 cases of out-ofhospital cardiac arrest as a result of a variety of causes only seven patients survived $(3 \%)$ and among the 135 patients with cardiac aetiology only four survived $(3 \%)$. Ways to improve the outcome for out-of-hospital cardiac arrest are discussed.

Key words: out-of-hospital cardiac arrest, survival rate.

\section{INTRODUCTION}

Since the publication by Kouwenhoven ${ }^{1}$ of the usefulness of closed chest compression for cardiac arrest in the 1960s, there has been great interest in the application of this knowledge. Community cardiopulmonary resuscitation (CPR) programmes have flourished in many developed countries. In Hong Kong, both the St John Ambulance Association and the Red Cross offer many basic CPR courses for the public. Studies have shown that bystander CPR, when initiated early, improves survival of patients suffering from out-of-hospital cardiac arrest. $^{2,3}$ Survival rates of out-of-hospital cardiac arrest patients vary widely $(0-26 \%){ }^{4.5}$ The purpose of this study is to report our experience over a $21 / 2$ year period.

Correspondence:

T.W. Wong,

Consultant, Accident and Emergency

Department, Kwong Wah Hospital, 25 Waterloo Road, Yaumati, Kowloon, Hong Kong.

\section{STUDY SETTING}

Kwong Wah Hospital is situated in the densely populated city centre on the Kowloon Peninsular. The catchment area is about 5 square kilometres with an estimated population of over 450000 . About $15 \%$ of patients are over 60 years old. The A\&E department has an annual attendance of around 130000.

Hong Kong has a population of around 6 million and the male to female ratio is 1.04 . The population is becoming older and in $199217 \%$ of the population were older than 55 years. The death rate per 100000 population was 54.7 in 1992 of which $10.4 \%$ were attributed to ischaemic heart disease (ICD 410414). The proportion of citizens with basic CPR training is not known.

During the study period our pre-hospital emergency medical system (EMS) was basically a onetier system staffed by ambulance personnel. The ambulance service is run by the Fire Service Department in Hong Kong. Citizens can gain access to the system by dialling ' 999 '. The ambulance personnel are required to attend a 24-week training programme before being placed into active service. They are instructed to begin external cardiac massage and airway management in patients who have suffered out-of-hospital cardiac arrests. They are allowed to insert an oral airway and to ventilate patients with a pressure cycled Stephenson Minuteman ventilator using a CPR head. They are not allowed to intubate or to administer drugs, nor are they allowed to cease resuscitation efforts in the field.

\section{METHOD}

All out-of-hospital cardiac arrest patients brought in by ambulance and resuscitated during the 30-month period from 1 June 1990 to 30 November 1992 were included. Patients who were clinically judged to be beyond resuscitation (e.g. rigor mortis, decomposition, dependent lividity) were certified as Death Before Arrival and were excluded from the present study.

Standard record sheets were used for patients who were resuscitated in the department. This study was started before the Utstein style was promul- 
Out of hospital cardiac arrest gated. ${ }^{7}$ Terminology and definitions used in this report conform to those recommended by the Utstein style as far as possible. Differences in definitions are specified below. Information collected included age, sex, initial rhythm on arrival, treatment given and (after December 1990) whether the arrest was witnessed. The time when cardiac arrest occurred was difficult to ascertain reliably and was therefore not included. Records of time intervals before arrival in the A\&E department were also not available. Initial rhythm was defined as the first rhythm recorded after arrival at the department since ECG monitors were usually unavailable in the ambulance.

Patients who were admitted to the intensive care unit/ward after return of spontaneous circulation were followed up by the authors to determine the outcome. Causes of death were traced from the pathology department when post-mortem examinations were performed. Otherwise, the diagnoses stated on the death certificates were used. For patients who were certified dead in the A\&E department, causes of death were ascertained by the forensic pathologist. Survival was defined as patients discharged alive to either their home or to some extended care facilities. Data about cerebral performance at discharge were unavailable.

\section{RESULTS}

A total of 648 out-of-hospital cardiac arrest patients were brought in by ambulance during the study period. Out of these 648 patients only $263(40 \%)$ were resuscitated. Within this group $135(51 \%)$ had a cardiac aetiology for their arrest (Table 1).

For the group, which included all causes of death (all causes group), the average age was 64 years and $68 \%$ of the patients were male. For the group of patients with cardiac aetiology (cardiac causes group) the average age was 69.5 years with $72 \%$ of patients being male (Table 2).

Asystole was the most common initial rhythm monitored (around 70\%). Ventricular fibrillation (VF) occurred in $12 \%$ in the all causes group and $19 \%$ in the cardiac causes group.

Return of spontaneous circulation and admission to the ward was achieved in $34 \%$ patients in VF for the all causes group. For the cardiac causes group $32 \%$ of patients in VF were admitted. Patients presenting with other initial rhythms (mainly pulseless electrical activity) had the highest survival to admission rate of around $70 \%$ for both groups. This result was surprising and could be because of misclassification of rhythm by the doctor on duty. No patient in the other rhythm group survived. Out of the total 263 patients presenting to the A\&E department only seven (3\%) were discharged alive. Of the 135 cases with a cardiac cause only four $(3 \%)$ survived.

The circumstances of the arrest were known in 199 patients and among them 114 (57\%) were witnessed. Within this witnessed arrest group 18 $(16 \%)$ presented with VF/VT on arrival; in the unwitnessed group only $8 \%$ were in VF/VT $(P<0.05)$. Return of spontaneous circulation and admission to ward was achieved in $50(57 \%)$ of patients in the witnessed arrest group as compared with $17(20 \%)$ in the unwitnessed group $(P<0.005)$ (Table 3$)$.

\section{DISCUSSION}

Heart disease accounted for $51 \%$ of the out-ofhospital cardiac arrests in our study which is expected as this is the second major cause of death in Hong Kong after malignancy. Aneurysms are not a common cause of death in Hong Kong and it was interesting to note that all the 10 cases were only diagnosed at post-mortem. Respiratory disease, notably obstructive airway disease, is also important as a cause of out-of-hospital cardiac arrest. Perhaps, more effort should be made by doctors to educate these patients on the warning signals of severe attacks. Trauma was an infrequent cause of death in this study, possibly because of the slow traffic in this very busy district.

The survival rate for out-of-hospital cardic arrest, as reported in the literature, varies. In a study of $\mathbf{2 1 6}$ cases in Brighton there was only one survivor ${ }^{8}$ whereas, the survival rate was as high as $26 \%{ }^{9}$ for the King County series, which consisted of 1297 cases.

One of the main variables that affects the success rate is the organization of the emergency medical system (EMS). The EMS, with one tier of emergency medical technicians (EMT) providing basic life support has the worst rate of success and systems with two tiers, consisting of EMT and paramedics providing advanced life support, have the best results. ${ }^{9}$ At the time of the present study our system belonged to the basic EMT classification. We compared our resuts with other countries with similar systems (Table 4) and the discharged alive rate for all rhythm groups was comparable.

In a Chicago study of outcome for out-of-hospital arrest in cities with populations of over 1 million, the survival rate was only $2 \%$ out of 3221 cases. An earlier study with 300 cases in Los Angeles however, 
T.W. Wong \& K.C.

Yeung

\begin{tabular}{|c|c|c|c|c|}
\hline Diagnosis & Clinical & Post-mortem & Total & $(\%)$ \\
\hline \multicolumn{5}{|l|}{ Heart Disease } \\
\hline Myocardial infarction & 21 & 18 & 39 & 15 \\
\hline Ischemic heart disease & 26 & 38 & 64 & 24 \\
\hline Hypertensive heart disease & 8 & 11 & 19 & 7 \\
\hline Heart failure & 8 & 0 & 8 & 3 \\
\hline Cardiomyopathy & 0 & 1 & 1 & 0 \\
\hline Myocarditis & 0 & 1 & 1 & 0 \\
\hline Other & 3 & 0 & 3 & 1 \\
\hline Dissecting aneurysm & 0 & 5 & 5 & 2 \\
\hline Rupture aortic aneurysm & 0 & 5 & 5 & 2 \\
\hline \multicolumn{5}{|l|}{ Chronic obstructive airway } \\
\hline disease & 12 & 13 & 25 & 10 \\
\hline Pneumonia & 4 & 10 & 14 & 5 \\
\hline Aspiration & 2 & 0 & 2 & 1 \\
\hline Tension pneumothorax & 1 & 0 & 1 & 0 \\
\hline Pulmonary embolism & & 1 & 1 & \\
\hline Stroke & 5 & 7 & 12 & 5 \\
\hline Epilepsy & 0 & 3 & 3 & 1 \\
\hline Malignancies & 7 & 2 & 9 & 3 \\
\hline Narcotic overdose & 0 & 2 & 2 & 1 \\
\hline Poisoning & 1 & 2 & 3 & 1 \\
\hline Electrocution & 1 & 2 & 3 & 1 \\
\hline Trauma & 10 & 12 & 22 & 8 \\
\hline Anaphylaxis & 1 & 0 & 1 & 0 \\
\hline Pending & & 7 & 7 & 3 \\
\hline Unknown & & 9 & 9 & 3 \\
\hline \multicolumn{5}{|l|}{ Miscellaneous } \\
\hline Holt-Oram syndrome & 1 & & 1 & 0 \\
\hline Chronic renal failure & 1 & & 1 & 0 \\
\hline Pulmonary fibrosis & & 1 & 1 & 0 \\
\hline Septicaemia & & 1 & 1 & 0 \\
\hline Total & 112 & 151 & 263 & 100 \\
\hline
\end{tabular}

Table 1. Causes of death yielded a better result of $10 \% .{ }^{5}$ Hong Kong is also plagued with all sorts of access problems, e.g. traffic jams, high rise buildings with a small lift or no lift at all etc. In a recent study in Arizona, it was reported that nearly half the on-scene time was spent accessing and removing patients. In Hong Kong, this could take even longer.

Experts in the field of pre-hospital care have propounded the concept of 'chain of survival' in the understanding of successful resuscitation of out-ofhospital cardiac arrests. ${ }^{10}$ The first chain is 'early access' which is the summation of the process of early recognition and prompt EMS response. According to a study of ambulance services in Hong Kong reported in $1986,{ }^{11}$ the call to despatch interval was estimated to be $3 \mathrm{~min}$. This was significantly longer than the $1 \mathrm{~min}$ recommended. ${ }^{12}$ It was also reported that $95 \%$ of the destinations could be reached within $14 \mathrm{~min}$ and $50 \%$ could be reached within $7 \mathrm{~min}$ from the call being received in Kowloon where the hospital is situated. In comparison with other places our average call-response 
Out of hospital cardiac arrest
Table 2. Comparison of results for all causes and cardiac causes of arrest

\begin{tabular}{lcc}
\hline & All causes & Cardiac causes \\
\hline Number of cases & 263 & 135 \\
Average age & 64 & 69.5 \\
Male & & \\
Female & $180(68 \%)$ & $97(72 \%)$ \\
& $83(32 \%)$ & $38(28 \%)$ \\
Initial rhythm & & \\
Asystole & $182(69 \%)$ & $90(67 \%)$ \\
V.F. & $32(12 \%)$ & $25(19 \%)$ \\
V.T. & $3(1 \%)$ & $3(2 \%)$ \\
Other & $46(17 \%)$ & $17(13 \%)$ \\
Ward admission & & \\
Asystole & & \\
V.F. & $41(23 \%)$ & $27(30 \%)$ \\
V.T. & $11(34 \%)$ & $8(32 \%)$ \\
Other & $1(33 \%)$ & $1(33 \%)$ \\
Discharged & $31(67 \%)$ & $12(71 \%)$ \\
Alive & $7(3 \%)$ & $4(3 \%)$ \\
\hline
\end{tabular}

Table 3. Comparison of results for witnessed vs. unwitnessed arrest

\begin{tabular}{lcrrr}
\hline & $\begin{array}{c}\text { Ward } \\
\text { admission }\end{array}$ & Fail & Survive & Total \\
\hline Witnessed & 50 & 61 & 3 & 114 \\
Unwitnessed & 17 & 66 & 2 & 85 \\
*Total & 67 & 127 & 5 & 199 \\
\hline & Asystole & VF/VT & Other & Total \\
& 69 & 18 & 27 & 114 \\
\hline Witnessed & 67 & 7 & 11 & 85 \\
Unwitnessed & 136 & 25 & 38 & 199 \\
**Total & & & & \\
\hline$* \chi^{2}=12.6940, P<0.005$ & & & \\
$* * \chi^{2}=7.54025, P<0.05$ & & &
\end{tabular}

time of $10 \mathrm{~min}$ was long $^{4.12}$ (Table 4) and was certainly longer than the 4 min recommended by experts. The despatch system of the Fire Service Department has recently been computerized and hopefully the call to despatch interval will shorten. Further decrease in response time is obviously desirable but costly.

The second variable in the chain of survival is early CPR. Many studies have indicated the usefulness of immediate bystander CPR in improving systematically look into this factor but our impression was that bystander CPR was seldom practised in our patient population. This was reflected in our low initial VF rate $(12 \%)$ despite the fact that $57 \%$ of our cases were witnessed arrests (Table 4). Several approaches were suggested to improve the bystander CPR rate. ${ }^{9}$ The first was community-based CPR training as organized by the Red Cross etc. According to estimations made by the American Heart Association an adult CPR uptake rate of $20 \%$ in a community would be effective to decrease mortality and morbidity because of out-of-hospital cardiac arrest. It was our impression that the uptake rate in Hong Kong was much lower when compared with the United States. The second approach is to target CPR training to those who are more likely to come across cardiac arrests, e.g. staff of old people's homes and spouses of cardiac patients. A third approach is despatcher-assisted CPR using a telephone link.

The third factor in the chain of survival is early defibrillation. ${ }^{10.13,14}$ Since January 1991, some of our ambulances were equipped with automatic external defibrillators. In a preliminary study by Lo et al., ${ }^{15}$ there was no significant increase in the number of patients successfully resuscitated and admitted into hospital compared with ordinary ambulances without defibrillators. Brison ${ }^{16}$ likewise did not find a significant increase in survival after the introduction of defibrillators. Both papers stressed the importance of improvement in other elements in the chain of survival.

The final variable in the chain of survival is early advanced care which includes intravenous access, endotracheal intubation and administration of emergency drugs. With an average call-response time of $10 \mathrm{~min}$ and an average scene-to-hospital time of $15 \mathrm{~min}$ the arrest-to-advanced cardiac life support time could be as long as $25 \mathrm{~min}$ in our setting, which is obviously not desirable. A new batch of ambulance personnel have been upgraded to the North American equivalent of EMT-intermediate level. It will probably be a long time before ambulance staff are trained to paramedic level. On the other hand, an Edinburgh group ${ }^{17}$ has found a hospital-based flying squad to be a feasible and economical alternative to training paramedics. This option is probably worth considering in Hong Kong.

Cost-effectiveness analyses are important when contemplating improvements in our pre-hospital emergency medical system. ${ }^{18.19}$ From overseas studies, the addition of a defibrillator operated by ambulance personnel was cost-effective. Further 
T.W. Wong \& K.C. Yeung

\begin{tabular}{|c|c|c|c|c|c|}
\hline Study & $\begin{array}{l}\text { No. of } \\
\text { attempted } \\
\text { CPR }\end{array}$ & $\begin{array}{c}\text { Average } \\
\text { age (years) }\end{array}$ & $\begin{array}{c}\text { Male } \\
\text { patients } \\
(\%)\end{array}$ & $\begin{array}{c}\text { Arrest } \\
\text { witnessed } \\
(\%)\end{array}$ & $\begin{array}{l}\text { Average } \\
\text { call- } \\
\text { response } \\
\text { interval } \\
\text { (min) }\end{array}$ \\
\hline \multicolumn{6}{|l|}{ Basic EMT } \\
\hline K.W.H. & 263 & 64 & 68 & 57 & $13^{11}$ \\
\hline Durham $/ 84^{4}$ & 126 & - & - & 47 & 6.5 \\
\hline Minnesota/86 & 118 & - & 79 & 100 & - \\
\hline Vancouver $/ 78^{4}$ & 110 & - & - & - & - \\
\hline Winnipeg $/ 80^{4}$ & 849 & - & - & - & - \\
\hline \multicolumn{6}{|l|}{ Paramedic } \\
\hline Los Angeles $/ 83^{4}$ & 300 & 65 & 68 & 41 & 5 \\
\hline Chicago/90 5 & 3221 & 67 & 56 & 43 & 6 \\
\hline Ontario/92 ${ }^{16}$ & 1510 & - & 68 & 80 & 7.8 \\
\hline Study & $\begin{array}{c}\text { With } \\
\text { bystander } \\
\text { CPR (\%) }\end{array}$ & $\begin{array}{c}\text { No. in all } \\
\text { rhythms } \\
\text { discharged (\%) }\end{array}$ & $\begin{array}{r}\text { No. in } \\
(\%\end{array}$ & $\begin{array}{l}\text { V.F. } \\
\text { \%) }\end{array}$ & $\begin{array}{l}\text { No. in V.F. } \\
\text { lischarged } \\
\quad(\%)\end{array}$ \\
\hline \multicolumn{6}{|l|}{ Basic EMT } \\
\hline K.W.H. & $?$ & $7(3)$ & 32 & (12) & $5(15)$ \\
\hline Durham $/ 84^{4}$ & 35 & $11(9)$ & 61 & (48) & $7(11)$ \\
\hline Minnesota/ $/ 86^{4}$ & 37 & $3(3)$ & - & - & - \\
\hline Vancouver $/ 78^{4}$ & 16 & $6(6)$ & - & - & - \\
\hline Winnipeg/80 4 & - & $33(4)$ & 226 & (27) & $24(11)$ \\
\hline \multicolumn{6}{|l|}{ Paramedic } \\
\hline Los Angeles $/ 83^{4}$ & 35 & $30(10)$ & 135 & (45) & $19(14)$ \\
\hline Chicago/90 $/ 95$ & 18 & $55(2)$ & 754 & (23) & $29(4)$ \\
\hline Ontario/92 ${ }^{16}$ & & $38(2.5)$ & - & - & - \\
\hline
\end{tabular}

decreases in the call-response time after a certain limit may not be as cost-effective. More local studies are required in order to find the most cost-effective method to improve survival. In the mean time health care professionals should take the lead to better educate the public on the early recognition of impending arrest and the importance of calling for help immediately. Community efforts to learn basic CPR should also be encouraged.

\section{ACKNOWLEDGEMENTS}

We would like to thank Dr Elaine Gwi (Consultant Pathologist, KWH) and Dr David Yip (Consultant Forensic Pathologist) for their assistance in identifying the causes of death of patients in this study.

\section{REFERENCES}

1. Kouwenhoven W.B., Jude J.R. \& Knickerbocker G.G. (1960) Closed-chest cardiac massage. Journal of
Table 4. Patient characteristics and survival from out-of hospital cardiac arrest with different systems
American Medical Association 173, 1064-1067.

2. Cummins R.O. \& Eisenberg M.S. (1985) Prehospital cardiopulmonary resuscitation: Is it effective? Journal of American Medical Association 253, 2408-2412.

3. Spaite D.W., Criss A.E., Wright A.L., Keeley K.T. \& Meislin H.W. (1990) Pre-hospital cardiac arrest: The impact of witnessed collapse and bystander CPR in a metropolitan EMS system with short response times. Annals of Emergency Medicine 19, 1264-1269.

4. Eisenberg M.S., Horwood B.T., Cummins R.O., Reynolds-Haertle R. \& Hearne T.R. (1990) Cardiac arrest and resuscitation: A tale of 29 cities. Annals of Emergency Medicine 19, 179-186.

5. Becker L.B., Ostrander M.P., Barrett J. \& Kondos G.T. (1991) Outcome of CPR in a large metropolitan area - Where are the survivors? Annals of Emergency Medicine 20, 355-361.

6. Hospital Authority (1994) Hospital Authority Statistical Report 1992/93.

7. Cummins R.O., Chamberlain D.A., Abramson N.S. et al. (1991) Recommended guidelines for uniform reporting of data from out-of-hospital cardiac arrest: The Utstein style. Circulation 84(2), 960-973. 
Out of hospital cardiac arrest
8. White N.M., Parker W.S., Binning R.A., et al. (1973) Mobile coronary care provided by ambulance personnel. British Medical Journal 3, 618-622.

9. Cummins R.O., Eisenberg M.S., Hallstrom A.P. et al (1985) Survival of out-of-hospital cardiac arrest with early initiation of cardiopulmonary resuscitation. American Journal of Emergency Medicine 3, 114-118.

10. Cummins R.O., Ornato J.P., Thies W.H. \& Pepe P.E. (1991) Improving surival from sudden cardiac arrest: The 'chain of survival' concept. Circulation 83, 1832-1847.

11. Raitt B. \& Vicary M. (1986) Review of Hong Kong Ambulance Service, Final Report. Fire Service Department, Hong Kong Government.

12. Becker L.B. \& Pepe P.E. (1993) Ensuring effectiveness of community-wide emergency cardiac care. Annals of Emergency Medicine 22(2), 354-65.

13. Weaver W.D., Hill D., Fahrenbruch C.E. et al (1988) Use of the automatic external defibrillator in the management of out-of-hospital cardiac arrest. New England Journal of Medicine 319, 661-666.

14. Cobbe S.M., Redmond M.J., Watson J.M., Hollingworth J. \& Carrington D.J. (1991) 'Heartstart Scotland' initial experience of a national scheme for out of hospital defibrillation. British Medical Journal 302 , 517-1520.

15. Lo Y.S.A., Hui W.K., Yeung S. \& Au-yeung H.L. (1993) All ambulance crew should receive full paramedic training - Defibrillation training is just a step forward. Hong Kong College of Cardiology Inaugural Scientific Congress Proceedings.

16. Brison R.J. et al. (1992) Cardiac arrest in Ontario: circumstances, community response, role of prehospital defibrillation and predictor of survival. Canadian Medical Association Journal 147, 191-199.

17. Cusack S., Steedman D.J., Robertson C.D. \& Little K. (1992) Flying Squad response to out-of-hospital cardiac arrest - a decade of experience. Archives of Emergency Medicine 9(2), 203-207.

18. Valenzuela T.D., Criss E.A., Spaite D., Meislin H.W. Wright A.L. \& Clark L. (1990) Cost-effectiveness analysis of paramedic emergency medical services in the treatment of prehospital cardiopulmonary arrest. Annals of Emergency Medicine 19, 1407-1411.

19. Anderson I.W.R., Black R.J., Ledingham I.M. et al (1987) Early emergency care study: the potential and benefits of advanced prehospital care. British Medical Journal 294, 228-231. 